Negative Anthropologie 


\section{Philosophische Anthropologie}

Herausgegeben von

Hans-Peter Krüger und Gesa Lindemann

Wissenschaftlicher Beirat:

Richard Shusterman (Philadelphia) und Gerhard Roth (Bremen)

\section{Band 12}




\section{Negative \\ Anthropologie}

Ideengeschichte und Systematik einer unausgeschöpften Denkfigur

Herausgegeben von

Hannes Bajohr und Sebastian Edinger

\section{DE GRUYTER}


ISBN 978-3-11-071687-0

e-ISBN (PDF) 978-3-11-071694-8

e-ISBN (EPUB) 978-3-11-071701-3

ISSN 2191-9275

Library of Congress Control Number: 2021947012

Bibliografische Information der Deutschen Nationalbibliothek

Die Deutsche Nationalbibliothek verzeichnet diese Publikation in der Deutschen Nationalbibliografie; detaillierte bibliografische Daten sind im Internet über http://dnb.dnb.de abrufbar.

(C) 2021 Walter de Gruyter GmbH, Berlin/Boston

Druck und Bindung: $\mathrm{CPI}$ books $\mathrm{GmbH}$, Leck

www.degruyter.com 